Research Article

\title{
Nanoparticles Synergistic Effect with Various Substrate Pretreatment and their Comparison on Biogas Production from Algae Waste
}

\author{
Asad A. Zaidi 1,2, Sohaib Z. Khan ${ }^{3, *}$, Hamad Almohamadi ${ }^{4}$, Essam R.I. Mahmoud ${ }^{3}$, \\ Muhammad N. Naseer ${ }^{1}$
}

${ }^{1}$ Department of Engineering Sciences, PN Engineering College, National University of Sciences and Technology, Karachi, Pakistan.

${ }^{2}$ College of Power and Energy Engineering, Harbin Engineering University, Harbin 150001, China.

${ }^{3}$ Department of Mechanical Engineering, Faculty of Engineering, Islamic University of Madinah, Madinah, Saudi Arabia.

${ }^{4}$ Department of Chemical Engineering, Faculty of Engineering, Islamic University of Madinah, Madinah, Saudi Arabia.

Received: 18th March 2021; Revised: 22nd April 2021; Accepted: $23^{\text {rd }}$ April 2021

Available online: 25 th April 2021; Published regularly: June 2021

\section{Abstract}

Algae waste is one of the potential substrates for biogas and biohydrogen production and can comprehend multiple benefits of waste treatment and resource utilization. In view of the key bottlenecks such as low substrate degradation rate and poor productivity of algae waste production process, this study analyzes the combined effect of two metallic and metallic oxide nanoparticles with different substrate pretreatment methods (autoclave, ultrasonic, and microwave methods) to investigate the effect of anaerobic digestion of green algae (Enteromorpha). The results showed that out of the three pretreatment methods, microwave pretreatment and nanoparticles' synergistic effect significantly increases biogas production. The microbial community composition at the phylum level was analyzed. It was observed that the Firmicutes were most abundant across all samples. The relative abundance of Firmicutes for control, Ni NPs + MW, Co NPs + MW, and $\mathrm{Fe}_{3} \mathrm{O}_{4} \mathrm{NPs}+\mathrm{MW}$ groups were 51.78, 70.37, 75.77, and 83.93\%, respectively. The second most abundant was of Bacteroidetes that also contributes to hydrogen production. This relatively high abundance of Firmicutes and Bacteroidetes promises its potential applications in a hydrogen production facility.

Copyright (C) 2021 by Authors, Published by BCREC Group. This is an open access article under the CC BY-SA License (https://creativecommons.org/licenses/by-sa/4.0).

Keywords: Algae; Anaerobic Digestion; Biomass; Biogas; Nanoparticles; Pretreatment

How to Cite: A.A. Zaidi, S.Z. Khan, H. Almohamadi, E.R.I. Mahmoud, M.N. Naseer (2021). Nanoparticles Synergistic Effect with Various Substrate Pretreatment and their Comparison on Biogas Production from Algae Waste. Bulletin of Chemical Reaction Engineering \& Catalysis, 16(2), 374-382 (doi:10.9767/bcrec.16.2.10637.374-382)

Permalink/DOI: https://doi.org/10.9767/bcrec.16.2.10637.374-382

\section{Introduction}

The world is facing a significant energy crisis due to increased energy demand [1,2]. The con-

\footnotetext{
* Corresponding Author.

Email: szkhan@iu.edu.sa (Sohaib Z. Khan)

Telp: +96655618 5916
}

ventional sources alone cannot fulfill this everincreasing demand for energy because conventional energy sources are mostly nonrenewable energy sources that tend to deplete with time [3]. Therefore, it is a fact that there is a great need for energy sources that do not deplete and damage the environment [4,5]. Renewable energy sources are, on the other hand, eco-friendly. 
One such source for energy harvesting is biomass [6].

Biofuels can be produced by utilizing locally available organic feedstock [7]. Various methods are available for organic matter to energy conversion, but Anaerobic Digestion (AD) is among the most preferable, specifically for biogas production [8]. During anaerobic treatment, a variety of microorganisms work together to convert macromolecular organics into methane, carbon dioxide, water, hydrogen sulfide, and ammonia. In this process, the metabolic processes of different microorganisms interact and restrict each other to form a complex ecosystem [9]. Since 1970s, the scientific community has made great progress in the study of anaerobic microorganisms and their metabolic processes, and promoted the development of anaerobic biotechnology. The anaerobic degradation process of complex organic matter can be divided into four typical stages as shown in Figure 1.

Algae biofuel belongs to $3^{\text {rd }}$ generation of biofuels and is considered as one of the potential candidates for biofuel conversion [10]. However, strong, resilient walls of algae biomass make the conversion process difficult as it increases the hydrolysis stage and slows down the $\mathrm{AD}$ process [11]. In order to improve the biodegradability and to increase the conversion efficiency of the AD process, many pretreatment processes have been used in previous studies [12-15]. These include thermal, physical, biological, and chemical pretreatments of substrates before AD. Some studies also discussed the combined effect of two different techniques.

Nanotechnology has appeared as an intriguing field of science [16]. It can be applied in biofuel production for the purpose of increasing reaction kinetics by stimulating the catalytic activity of microorganisms. Nanomaterials also help in the solubilization of feedstock, chemical modification of organic matter, and the release of biopolymeric substances such as carbohydrates and proteins [17]. The application of NMs for biogas production can be one possible way for the sustainability of this renewable energy source for large-scale production. Several nanomaterials are used as an additive to enhance biogas production. The previous study by authors [18] showed that the introduction of nanoparticles (NPs) as catalysts in the AD process significantly enhanced biogas production. However, it was hard for NPs to break the green algae cell wall, limiting the anaerobic digestion process in hydrolysis. The intercellular polymeric compounds are not accessible to the bacteria (anaerobic) as their cells' external wall is extremely strong and resistant. Saxena [19] noticed the same behavior of algae wall during the study of Ag NPs impact on the algae membrane. The accumulation rate of algae inside the cell after breaking the algae wall is not much promising and is regarded as a major hurdle [19,20]. Therefore, it is crucial to understand how the cell wall of an alga behaves in the presence of NPs. To cater the mentioned problem, pretreatment on substrates with hard cell walls is always performed and recommended by researchers. A previous study of the authors [21] shows that microwave pretreatment of algae results in biogas production with an increment of a substantial quantity. Overall, there is a wide range of technologies for performing pretreatment, including mechanical methods, ultrasound methods, microwave methods, thermal methods, and mixed; but it is

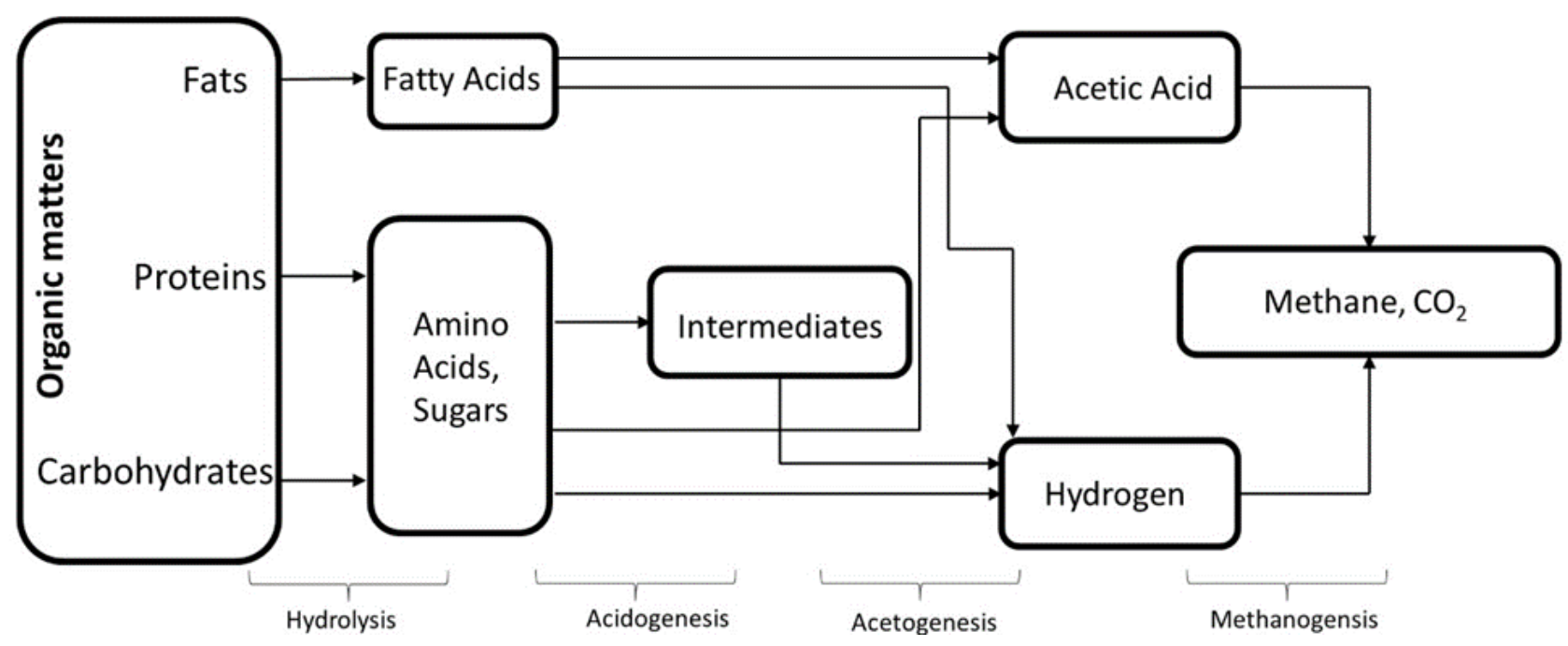

Figure 1. Outline of anaerobic digestion processes for methane production from organic matter. 
a costly and energy-intensive process. Researchers [20-23] have been emphasizing that to select the best pretreatment methods, the main contributing factors are cost and energy demand. For a practical implication, the energy balance needs to be positive. Using lower energy pretreatment methods have lower yield as compared to energy-intensive process [21]. Therefore, there is a need to develop such low energy and low-cost pretreatment methods that can ensure a positive energy cycle. In this regard, this study contributes to integrating ultrasonic (US), autoclave (AC), and microwave (MW) for energy demand reduction in the pretreatment of algae biomass and NPs.

\section{Materials and Methods}

\subsection{Raw Materials}

Aquatic algal biomass (Enteromorpha) in powdered form was obtained from the Institute of Hydrobiology, Chinese Academy of Science, Wuhan, China. For this study, the sludge from an Anaerobic-Anoxic-Oxic (AAO) reactor at Harbin Wenchang Sewage Treatment Plant, Harbin, China, was used. The acquired sample was then aeration cultivated with a ratio of 300:5:1 for a time of 14 days [24]. Moreover, VSS (Volatile Suspension Solids) and TSS (Total suspension solids) were observed to be 6420 and $2530 \mathrm{mg} / \mathrm{L}$, respectively. Every biodigester contained $60 \mathrm{ml}$ of anaerobic sludge with 20 grams of Enteromorpha powered.

Four different types of metallic ( $\mathrm{Ni}$ and $\mathrm{Co}$ ) and metallic oxide $\left(\mathrm{Fe}_{3} \mathrm{O}_{4}, \mathrm{MgO}\right)$ nanoparticles (NPs) were used in this study with spherical shape and an average size of less than $100 \mathrm{~nm}$. NPs were procured from China Metallurgical Research Institute, Beijing, China. The concentration of NPs in the biomass was optimized by response surface methodology [25]. Co and $\mathrm{Ni}$ NPs were added with the optimum value of 1 $\mathrm{mg} / \mathrm{L}$ each. On the other hand, the amount of $\mathrm{MgO}$ and $\mathrm{Fe}_{3} \mathrm{O}_{4}$ added was $10 \mathrm{mg} / \mathrm{L}$ each [18]. The same concentrations are used in this work. To decrease agglomeration of NPs, all the NPs suspensions were prepared with distilled water containing $0.1 \mathrm{mM}$ of sodium dodecylbenzene sulfonate.

\subsection{Experimental Setup}

The technique of batch system was adopted to carry out anaerobic studies. A thermostat steam bath vibrator (THZ-92A, China) was used for performing experiments. For about 120 hours, $500 \mathrm{~mL}$ anaerobic lab bottles (glass bottles) were employed as biodigesters. In order to create anaerobic conditions inside the bottle, the first rubber was used for sealing purposes, followed by five-minute $\mathrm{N}_{2}$ purging [11]. The digester's inside temperature set to $37^{\circ} \mathrm{C}$, and the mixing speed was about $150 \mathrm{rpm}$ [26]. To reduce the inclusion of error, each experiment was deliberately performed thrice, and average values were used. The MW pretreatment was performed before anaerobic digestion with a household Panasonic microwave oven (1180 $\mathrm{W})$. The AC pretreatment was performed with an Autoclaves Sterilizer (MJ-78A, STIK GROUP LLC, USA). The US pretreatment was carried out by using SONICS Vibra cell (VCX800, Sonics and Materials INC. USA). For MW, pretreatment was conducted for 3.5 minutes at $800 \mathrm{~W}$. For AC pretreatment, the condition was $30 \mathrm{~min}$ within $120^{\circ} \mathrm{C}$ temperature [27]. Moreover, the US pretreatment was carried out at $20 \mathrm{~Hz}$ for $3 \mathrm{~min}$ [28].

\subsection{Analytical Methods}

For the present study, high throughput sequencing was employed to analyze the microbial community. FastDNA ${ }^{\circledR}$ Spin Kit was used to acquiring the DNA samples followed by quality evaluation using the technique of absorbance ratio at A260/A280 and A260/A230 using a NanoDrop ND-2000 spectrophotometer [29,30]. Then the DNA samples were passed through a screening to select only those with a ratio $>1.8$ and 2.0 for A260/280 and A260/230, respectively. For the 16S ribosomal RNA (rRNA) gene PCR amplification, $\mathrm{tV} 3-\mathrm{V} 4$ regions of the bacterial 16S rRNA gene were amplified using the p r i m e r s e t $338 \mathrm{~F} \quad 5$, ACTCCTACGGGAGGCAGCAG-3 and 806R 5, GGACTACHVGGGTWTCTAAT-3. The PCR conditions were followed by Ma et al. [31]. The PCR product was loaded with index sequencing primers on a 300 -cycle $(2 \times 150$ paired ends) kit and run on a MiSeq. The resulting sequences were clustered into operational taxonomic units (OTUs) with the $97 \%$ similarity threshold [32].

In order to calculate the rate of cell lysis in the presence of NPs and various pretreatments; the following formula was employed [33]:

$$
\text { Cell Lysis Rate }(\%)=\frac{S C O D_{T}-S C O D_{0}}{T C O D_{0}-S C O D_{0}} \times 100
$$

where $\mathrm{SCOD}_{\mathrm{T}}$ is $\mathrm{SCOD}$ release during the $\mathrm{AD}$, $\mathrm{SCOD}_{\circ}$ is $\mathrm{SCOD}$ value for raw Enteromorpha, $\mathrm{TCOD}_{\mathrm{o}}$ is TCOD values for raw Enteromorpha. Total Solids (TS), Volatile Solids (VS), Chemical Oxygen Demand (COD), Soluble Chemical 
Oxygen Demand (SCOD), Total Chemical Oxygen Demand (TCOD), and reducing sugar were assessed as per the standard methods [34].

\section{Results and Discussion}

The primary purpose of US, AC, and MW pretreatment was to break the cell wall structure of algae to shorten the hydrolysis stage and increase the reaction rate. Scanning electron microscopy (SEM) was used to observe changes in the algae's physical structure, as shown in Figure 2. SEM micrograph indicated that the un-pretreated one (Control) had a compact structure with small holes on a smooth surface, whereas pretreated samples showed that the surface had irregular potholes. Also, the smaller particle size indicated Lingocellulosic structure, and applied pretreatment methods broke the substrates' surface. It can be observed that although AC pretreatment showed most cell wall rupture indicated that a large amount of physical activity affected the Ligno-
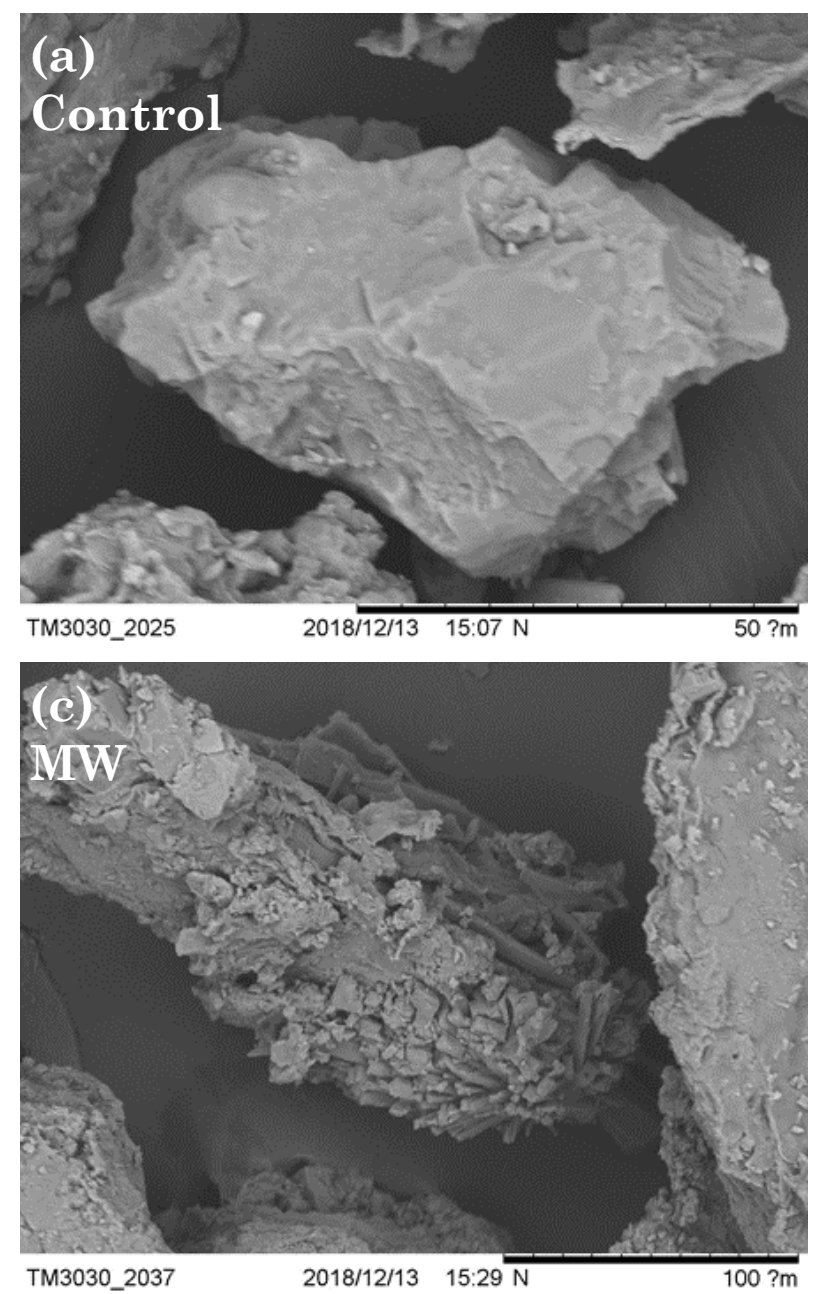

cellulosic structure of solid digestate and the surface of substrates was substantially damaged. However, the MW pretreatment resulted in a smaller size as well as decent cell distortion as compared to AC and US pretreatment techniques. It can also be observed that US pretreatment had less effect on cell wall rapture. After pretreatment of algae biomass, experiments were performed, and NPs were introduced into the biodigesters.

The cumulative biogas production by each combination of pretreatment method and NPs used in this study are shown in Figure 3. The Results showed that all combinations resulted in an increase in biogas yield except $\mathrm{MgO}$ NPs groups. This observation is in accordance with a study conducted by Wang et al. [35]. He used nano-MgO to study its impact on the AD's treated waste sludge and observed that there was a reduction of methane production by $98.92 \%$. Further, it was stipulated that the possible reason for this reduction is a release of $\mathrm{Mg}^{2+}$ in excess that contributes to the damaged
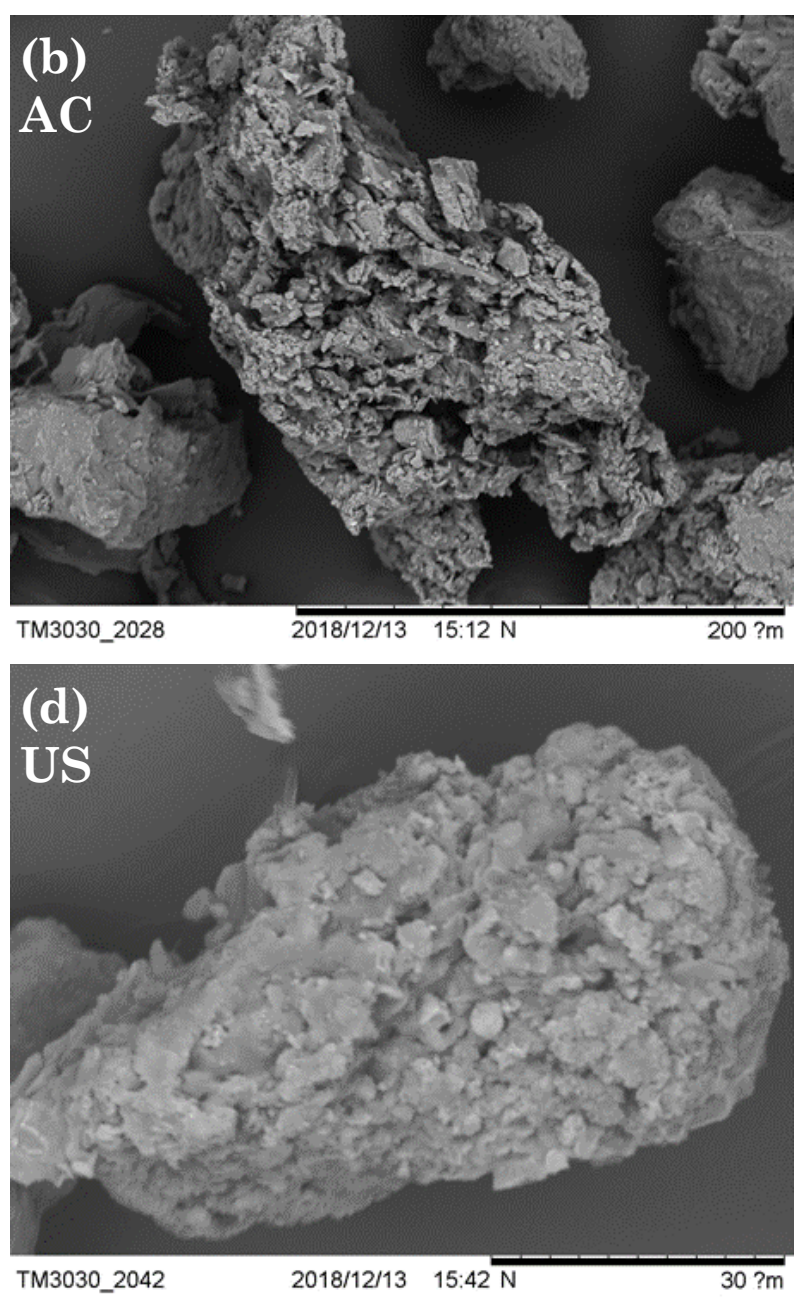

Figure 2. (a) Control or Untreated (b) Autoclave (AC) Pretreated (c) Microwave (MW) Pretreated and (d) Ultrasonic (US) Pretreated. 
cell membrane that ultimately results in loss of key enzymatic activities. MW pretreatment in combination with NPs significantly improved
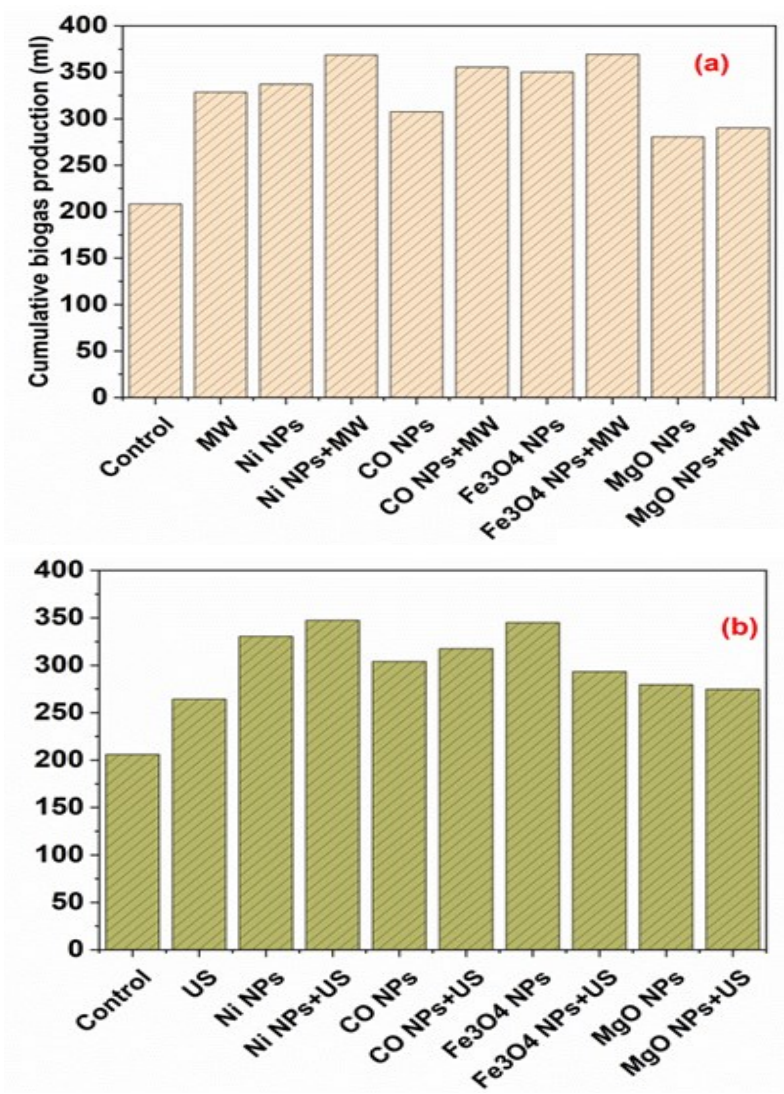

Figure 3. Synergistic effect on biogas production (a) MW Pretreatment + NPs (b) US Pretreatment + NPs and (c) AC Pretreatment + NPs.
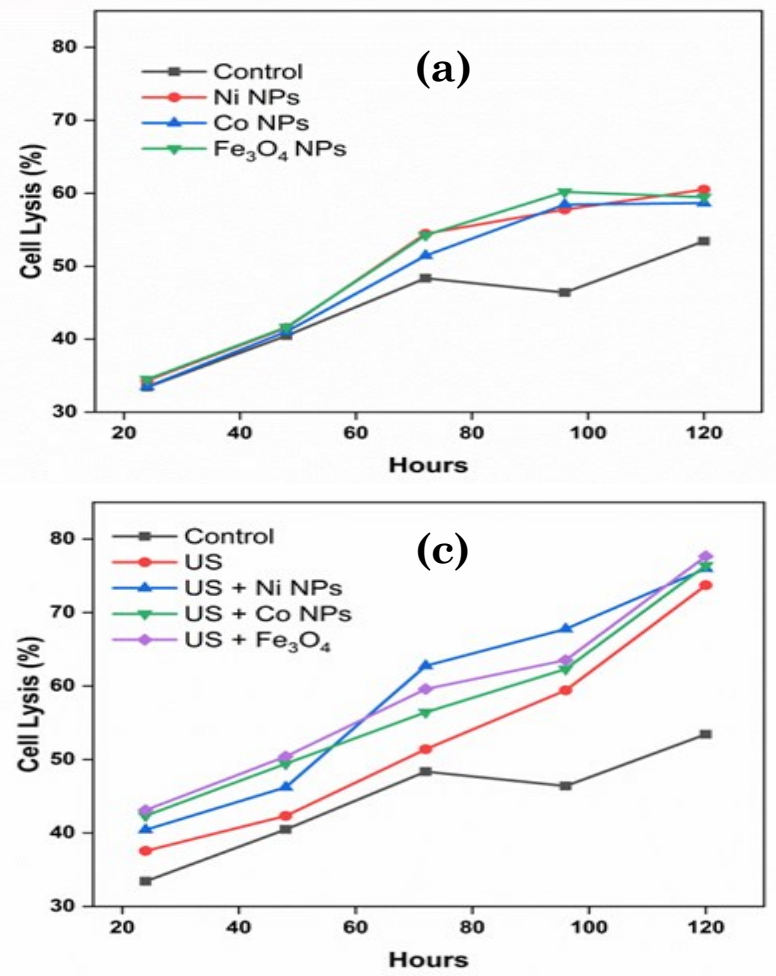

the biodegradability of Enteromorpha and provided more biogas yield as compared to other pretreatment and NPs combination. Ni NPs + MW Pretreatment group achieved the maximum biogas yield of $362 \mathrm{~mL}$ (1.76 times higher than control), whereas MgO NPs groups combined with pretreatment methods did not perform well. It is observed that pretreatment of MW results is early initiation of hydrolysis process in green algae that ultimately results in minimum lag time. Therefore, it is concluded that at the later stages of anaerobic digestion, NPs are much effective and have a positive impact. Microwave (MW) pretreatment is the transmission of electromagnetic energy in the
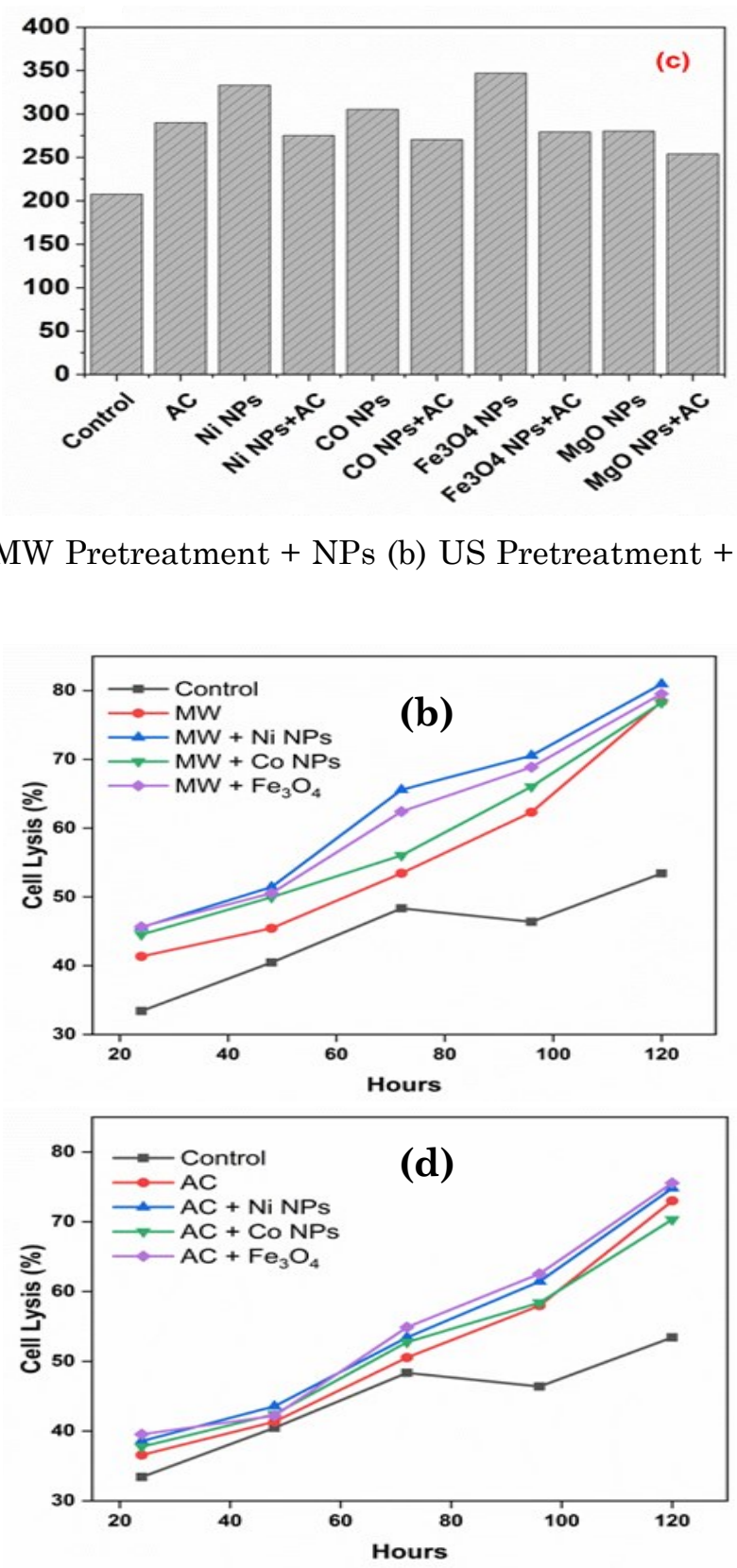

Figure 4. Cell Lysis rate (a) NPs (b) MW + NPs (c) US + NPs (d) AC + NPs. 
frequency range of 0.3 to $300 \mathrm{GHz}$. The $\mathrm{MW}$ pretreatment involves no contact amongst the source and the chemicals [36]. Compared with the conventional heating methods used, MW pretreatment provides higher heating efficiencies by direct interaction of microwaves with algae cells' walls [21]. Passos et al. [37] studied the effect of MW pretreatment on algae form High Rate Algal Ponds (HRAP). Results showed that MW pretreatment enhanced biogas production rate $(25-75 \%)$ and successfully improved the digestibility of biomass.

The increment in biogas production for the scenario of combined NPs and MW owes to the changes made by the selected pretreatment method. This MW pretreatment reacts with the external layer and dissolute it the release of cellulose, glycoproteins, and carbohydrates. Moreover, the lysis rate is also increased in this case, which results in increased biogas production [38]. In this process, MW pretreatment contributes by hydrolyzing the glycosidic bond of polysaccharides and carbohydrates. These hydrolyzed products, later on, are converted to sugars. Then, NPs do the trick by an inner braking layer of algae by hydrolyzation of cellulose into oligosaccharides [39]. When cell structure is disturbed, some compounds are released, such as proteins, lipids, and carbohydrates. These are then converted to amino acids, VFAs, and sugars [40].

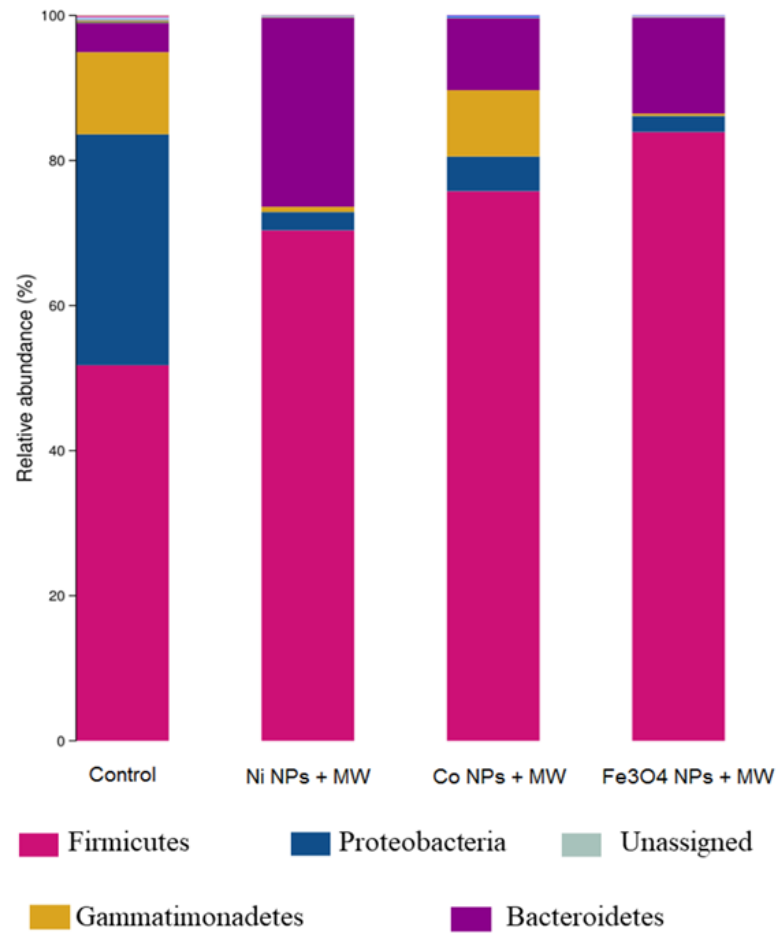

Figure 5. Microbial community composition of bacterial phyla.
The combined effect of different pretreatment methods with NPs on the biodegradability of algal biomass is determined by cell lysis rate, as shown in Figure 4. It can be observed from Figure 4 (a) that NPs had no significant effect on cell wall damage in comparison with control during the hydrolysis stage; NPs had a catalytic effect after 60 hours of the $\mathrm{AD}$ process. This result is in agreement with the previous study by authors [18]. Figure 4 (b) shows the results of combining MW pretreatment with NPs. The result shows an early dissolution of cell walls, resulting in the release of biopolymeric substances and increased biogas production. It can be observed that US pretreatment combined with NPs (Figure $4 \mathrm{c}$ ) also showed better cell wall damage and accordingly increased biogas production, whereas AC pretreatment combined with NPs (Figure $4 \mathrm{~d}$ ) showed low cell lysis rate, which resulted in low biogas yield.

In order to understand the mechanism, microbial community composition at the phylum level (relative abundance $>0.1 \%$ in all samples) is appraised and is shown in Figure 5. It was observed that the Firmicutes were most abundant across all samples. All combined NPs + MW pretreatment groups had more Firmicutes abundance as compared to the control group. The relative abundance of Firmicutes for control, Ni NPs + MW, Co NPs + MW, and $\mathrm{Fe}_{3} \mathrm{O}_{4}$ NPs + MW groups were found to be 51.78, $70.37,75.77$, and $83.93 \%$, respectively. Many of the Firmicutes can produce biohydrogen [41], and the higher abundance of Firmicutes indicates that the phenotypes of some microorganisms in the groups treated with NPs and MW pretreatment have mutated under the applied anaerobic digestion condition and can produce biohydrogen. The other dominant phylum was Bacteroidetes, which are well-known degraders of organic matter [42] and had influence on biogas production results of this study. The abundance of Bacteroidetes was lower in the control group than in combined NPs + MW pretreatment groups. The relative abundance of $\mathrm{Bac}$ teroidetes for control, Ni NPs + MW, Co NPs + $\mathrm{MW}$, and $\mathrm{F}_{\mathrm{e}} 3 \mathrm{O}_{4} \mathrm{NPs}+\mathrm{MW}$ groups were found to be $4.04,26.04,9.92$, and $13.24 \%$, respectively. Firmicutes and Bacteroidetes phyla have been identified as major hydrogen-producing bacteria with specific metabolisms which enable to maintain acceptable $\mathrm{H}_{2}$ performance [43]. Interestingly, the abundance of Proteobacteria is more in control than the rest of the groups indicating that this phylum has been replaced by the increasing abundance of $B a c$ teroidetes in other groups. The Bacteroidetes 
has more abundance in Ni NPs + MW pretreatment group.

\section{Conclusions}

This study has presented the synergistic influence of AC, US, and MW pretreatment with metal and metal oxide NPs on AD of Enteromorpha. The results showed that the combination of MW pretreatment with NPs has significantly reduced the lag phase and produced more biopolymer substances hence resulted in more biogas as compared to others. The microbial community analysis revealed that the Firmicutes were most abundant across all samples. All combined NPs + MW pretreatment groups had more Firmicutes abundance as compared to the control group. Firmicutes are followed by Bacteroidetes in terms of their abundance. Both are a good signal for hydrogen production applications.

\section{Acknowledgements}

The authors would like to thank the Scientific Research Deanship, the Islamic University of Madinah, for the support provided, with Tamayyuz 2 grant number 585 .

\section{References}

[1] Malik, A., Qureshi, S.R., Abbas, N., Zaidi, A.A. (2020). Energy and exergy analyses of a solar desalination plant for Karachi Pakistan. Sustainable Energy Technologies and Assessments , $\quad 37, \quad 100596$. D O I : 10.1016/j.seta.2019.100596.

[2] Mehdi, G., Ali, N., Hussain, S., Zaidi, A.A., Shah, A.H., Azeem, M.M. (2019). Design and Fabrication of Automatic Single Axis Solar Tracker for Solar Panel. In IEEE Xplore, 18530781. Sukkur, Pakistan: 2019 2nd International Conference on Computing, Mathematics and Engineering Technologies (iCoMET).

DOI: 10.1109/ICOMET.2019.8673496.

[3] Mushtaq, K., Zaidi, A.A., Askari, S.J. (2016). Design and performance analysis of floating dome type portable biogas plant for domestic use in Pakistan. Sustainable Energy Technologies and Assessments, 14, 21-25. DOI: 10.1016/j.seta.2016.01.001.

[4] Ahmed, S.F., Mushtaq, K., Ali, A. (2016). Design and performance analysis of floating dome type portable biogas plant for domestic use in Pakistan-manufacturing cost optimization. Biotechnology, 15, 112-118. DOI: 10.3923/biotech.2016.112.118.
[5] Mondial, C., Gie, D.E.L.É., Gadonneix, P., Kim, Y.D., Meyers, K., Ward, G., Frei, C. (2013). World Energy Resources 2013. London: World Energy Council.

[6] Cai, Y., Li, X., Zaidi, A.A., Shi, Y., Zhang, K., Feng, R., Lin, A., Liu, C. (2019). Effect of hydraulic retention time on pollutants removal from real ship sewage treatment via a pilotscale air-lift multilevel circulation membrane bioreactor. Chemosphere, 236, 124338. DOI: 10.1016/j.chemosphere.2019.07.069.

[7] Vasco-Correa, J., Khanal, S., Manandhar, A., Shah, A. (2018). Anaerobic digestion for bioenergy production: Global status, environmental and techno-economic implications, and government policies. Bioresource Technology, 247, 1015-1026. DOI: 10.1016/j.biortech.2017.09.004.

[8] Ma, H., Guo, Y., Qin, Y., Li, Y.-Y. (2018). Nutrient recovery technologies integrated with energy recovery by waste biomass anaerobic digestion. Bioresource Technology, 269, 520531. DOI: 10.1016/j.biortech.2018.08.114.

[9] Feng, R., Zaidi, A.A., Zhang, K., Shi, Y. (2018). Optimisation of Microwave Pretreatment for Biogas Enhancement through Anaerobic Digestion of Microalgal Biomass. Periodica Polytechnica Chemical Engineering, 63, 65-72. DOI: 10.3311/PPch.12334.

[10] Zaidi, A.A., Malik, A., Mushtaq, K., Ruizhe, F. (2018). Progress of Microalgal Biodiesel Research in Pakistan. Journal of Plant Science Current Research, 2, 2-7. DOI: 10.24966/PSCR-3743/100004

[11] Xia, A., Jacob, A., Tabassum, M.R., Herrmann, C., Murphy, J.D. (2016). Production of hydrogen, ethanol and volatile fatty acids through co-fermentation of macro- and micro-algae. Bioresource Technology, 205, $118-125 . \quad$ D O I : 10.1016/j.biortech.2016.01.025.

[12] Lee, K., Chantrasakdakul, P., Kim, D., Kong, M., Park, K.Y. (2014). Ultrasound pretreatment of filamentous algal biomass for enhanced biogas production. Waste Management, $\quad 34, \quad 1035-1040$. DO I : 10.1016/j.wasman.2013.10.012.

[13] Climent, M., Ferrer, I., Baeza, M.del.M., Artola, A., Vázquez, F., Font, X. (2007). Effects of thermal and mechanical pretreatments of secondary sludge on biogas production under thermophilic conditions. Chemical Engineering Journal, 133, 335-342. DOI: 10.1016/j.cej.2007.02.020.

[14] Passos, F., Felix, L., Rocha, H., Pereira, J.de.O., de Aquino, S. (2016). Reuse of microalgae grown in full-scale wastewater treatment ponds: Thermochemical pretreatment 
and biogas production. Bioresource Technology, $209, \quad 305-312$. D O I : 10.1016/j.biortech.2016.03.006.

[15] González-Fernández, C., Sialve, B., Bernet, N., Steyer, J.P. (2012). Thermal pretreatment to improve methane production of Scenedesmus biomass. Biomass and Bioenergy, 40, 105-111. DOI: 10.1016/j.biombioe.2012.02.008

[16] Antonio, F., Antunes, F., Gaikwad, S., Ingle, A.P. (2017). Nanotechnology for Bioenergy and Biofuel Production. Springer International Publishing, p. 3-18. doi:10.1007/978-3-31945459-7.

[17] Zaidi, A.A., Ruizhe, F., Malik, A., Khan, S.Z., Bhutta, A.J., Shi, Y., Mushtaq, K. (2019). Conjoint effect of microwave irradiation and metal nanoparticles on biogas augmentation from anaerobic digestion of green algae. International Journal of Hydrogen Energy, 44,

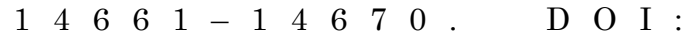
10.1016/j.ijhydene.2019.02.245.

[18] Zaidi, A.A., RuiZhe, F., Shi, Y., Khan, S.Z., Mushtaq, K. (2018). Nanoparticles augmentation on biogas yield from microalgal biomass anaerobic digestion. International Journal of Hydrogen Energy, 43, 14202-14213. DOI: 10.1016/j.ijhydene.2018.05.132.

[19] Saxena, P., Harish, H. (2018). Nanoecotoxicological Reports of Engineered Metal Oxide Nanoparticles on Algae. Current Pollution Reports, 4, 128-142. DOI: 10.1007/s40726-0180088-6.

[20] Chen, F., Xiao, Z., Yue, L., Wang, J., Feng, Y., Zhu, X., Wang, Z., Xing, B. (2019). Algae response to engineered nanoparticles: current understanding, mechanisms and implications. Environmental Science: Nano, 6, 1026-1042. DOI: $10.1039 / \mathrm{C} 8 \mathrm{EN} 01368 \mathrm{C}$.

[21] Zaidi, A.A., Feng, R., Malik, A., Khan, Z.S., Shi, Y., Bhutta, J.A., Shah, A.H. (2019). Combining Microwave Pretreatment with Iron Oxide Nanoparticles Enhanced Biogas and Hydrogen Yield from Green Algae. Processes, 7(1), 24. DOI: 10.3390/pr7010024.

[22] Passos, F., Hernández-Mariné, M., García, J., Ferrer, I. (2014). Long-term anaerobic digestion of microalgae grown in HRAP for wastewater treatment. Effect of microwave pretreatment. Water Research, 49, 351-359. DOI: 10.1016/j.watres.2013.10.013.

[23] Mendez, L., Mahdy, A., Demuez, M., Ballesteros, M., González-Fernández, C. (2014). Effect of high pressure thermal pretreatment on Chlorella vulgaris biomass: Organic matter solubilisation and biochemical methane potential. Fuel, 117, 674-679. DOI: 10.1016/j.fuel.2013.09.032.
[24] Esquivel-Elizondo, S., Ilhan, Z.E., GarciaPeña, E.I., Krajmalnik-Brown, R. (2017). Insights into Butyrate Production in a Controlled Fermentation System via Gene Predictions. MSystems, 2, e00051-17. DOI: 10.1128/mSystems.00051-17.

[25] Zaidi, A.A., Khan, S.Z., Shi, Y. (2021). Optimization of nickel nanoparticles concentration for biogas enhancement from green algae anaerobic digestion. Materials Today: Proceedings, 39, 1025-1028. DOI: 10.1016/j.matpr.2020.04.762.

[26] Abdelsalam, E., Samer, M., Attia, Y.A., Abdel-hadi, M.A., Hassan, H.E., Badr, Y. (2016). Comparison of nanoparticles effects on biogas and methane production from anaerobic digestion of cattle dung slurry. Renewable Energy, 87, 592-598. D O I : 10.1016/j.renene.2015.10.053.

[27] Fang, W., Zhang, P., Zhang, X., Zhu, X., van Lier, J.B., Spanjers, H. (2018). White rot fungi pretreatment to advance volatile fatty acid production from solid-state fermentation of solid digestate: Efficiency and mechanisms. Energy, $162, \quad 534-541$. DOI : 10.1016/j.energy.2018.08.082.

[28] Ometto, F., Quiroga, G., Pšenička, P., Whitton, R., Jefferson, B., Villa, R. (2014). Impacts of microalgae pre-treatments for improved anaerobic digestion: Thermal treatment, thermal hydrolysis, ultrasound and enzymatic hydrolysis. Water Research, 65, 350-361. DOI: 10.1016/j.watres.2014.07.040.

[29] Cai, Y., Ben, T., Zaidi, A.A., Shi, Y., Zhang, K., Lin, A., Liu, C. (2019). Effect of pH on Pollutants Removal of Ship Sewage Treatment in an Innovative Aerobic-Anaerobic MicroSludge MBR System. Water, Air, \& Soil Pollution, 230, 163. DOI: 10.1007/s11270-0194211-0.

[30] Zhang, Y., Xie, J., Liu, M., Tian, Z., He, Z., van Nostrand, J.D., Ren, L., Zhou, J., Yang, M. (2013). Microbial community functional structure in response to antibiotics in pharmaceutical wastewater treatment systems. Water Research, 47, 6298-6308. DOI: 10.1016/j.watres.2013.08.003.

[31] Ma, W., Han, Y., Ma, W., Han, H., Zhu, H., Xu, C., Li, K., Wang, D. (2017). Enhanced nitrogen removal from coal gasification wastewater by simultaneous nitrification and denitrification (SND) in an oxygen-limited aeration sequencing batch biofilm reactor. $\mathrm{Bi}$ oresource Technology, 244, 84-91. DOI: 10.1016/j.biortech.2017.07.083.

[32] Chen, J., Zhang, M., Li, F., Qian, L., Lin, H., Yang, L., Wu, X., Zhou, X., He, Y., Liao, B.-Q. (2016). Membrane fouling in a membrane bioreactor: High filtration resistance of gel layer 
and its underlying mechanism. Water Rese arch, $102, \quad 82-89$. D O I : 10.1016/j.watres.2016.06.028.

[33] Kavitha, S., Preethi, J., Banu J.R., Yeom, I.T. (2017). Low temperature thermochemical mediated energy and economically efficient biological disintegration of sludge: Simulation and prediction studies for anaerobic biodegradation. Chemical Engineering Journal, 317, 481-492. DOI: 10.1016/j.cej.2017.02.092.

[34] Chinese Environmental Protection Chief Bureau. (2002). Standard Methods for the Examination of Water and Waste Water. 4th ed. Beijing, China: Environmental Press.

[35] Wang, T., Zhang, D., Dai, L., Chen, Y., Dai, X. (2016). Effects of Metal Nanoparticles on Methane Production from Waste-Activated Sludge and Microorganism Community Shift in Anaerobic Granular Sludge. Scientific Reports, 6, 25857. DOI: 10.1038/srep25857.

[36] Appels, L., Houtmeyers, S., Degrève, J., Van Impe, J., Dewil, R. (2013). Influence of microwave pre-treatment on sludge solubilization and pilot scale semi-continuous anaerobic digestion. Bioresource Technology,128, 598-603. DOI: 10.1016/j.biortech.2012.11.007.

[37] Passos, F., Solé, M., García, J., Ferrer, I. (2013). Biogas production from microalgae grown in wastewater: Effect of microwave pretreatment. Applied Energy, 108, 168-175. DOI: 10.1016/j.apenergy.2013.02.042.

[38] Mahdy, A., Mendez, L., Ballesteros, M., González-Fernández, C. (2014). Enhanced methane production of Chlorella vulgaris and Chlamydomonas reinhardtii by hydrolytic enzymes addition. Energy Conversion and Management, 85, 551-557. DOI: 10.1016/j.enconman.2014.04.097.
[39] Ehimen, E.A., Holm-Nielsen, J.-B., Poulsen, M., Boelsmand, J.E. (2013). Influence of different pre-treatment routes on the anaerobic digestion of a filamentous algae. Renewable Energy, 50, 476-480. DO I : 10.1016/j.renene.2012.06.064.

[40] Kavitha, S., Kannah, R.Y., Yeom, I.T., Do, K.U., Banu, J.R. (2015). Combined thermochemo-sonic disintegration of waste activated sludge for biogas production. Bioresource Technology, 197, 383-392. DOI: 10.1016/j.biortech.2015.08.131.

[41] Fang, D., Zhao, G., Xu, X., Zhang, Q., Shen, Q., Fang, Z. (2018). Microbial community structures and functions of wastewater treatment systems in plateau and cold regions. $B i$ oresource Technology, 249, 684-693. DOI: 10.1016/j.biortech.2017.10.063.

[42] Thomas, F., Hehemann, J.-H., Rebuffet, E., Czjzek, M., Michel, G. (2011). Environmental and Gut Bacteroidetes: The Food Connection. Frontiers in Microbiology, 2, 93. DOI: 10.3389/fmicb.2011.00093.

[43] Cabrol, L., Marone, A., Tapia-Venegas, E., Steyer, J., Ruiz-filippi, G., Trably, E. (2017). Microbial ecology of fermentative hydrogen producing bioprocesses: useful insights for driving the ecosystem function. FEMS Microbiology Reviews, 41(2), 158-181. DOI: $10.1093 /$ femsre/fuw043.

Selected and Revised Papers from International Conference on Sustainable Energy and Catalysis 2021 (ICSEC 2021) (https://engineering.utm.my/chemicalenergy/icsec2021/) (School of Chemical and Energy Engineering, Faculty of Engineering, Universiti Teknologi Malaysia, 16-17th February 2021) after Peer-reviewed by Scientific Committee of ICSEC 2021 and Peer-Reviewers of Bulletin of Chemical Reaction Engineering \& Catalysis.

Editors (Guest) in this ICSEC 2021 section are Nor Aishah Saidina Amin, Mohd Asmadi Mohammed Yussuf, Salman Raza Naqui, while Editor in Chief is I. Istadi. 